\title{
Publications in Fake and Predatory Journals Harm Academic Reputation of Higher Education Institutions
}

\author{
Munad Jihad Ashij AL_Duliamy \\ MSc in Orthodontics \\ Assistant Professor - Mustansiriyah University / College of dentistry POP department
}

\section{Editorial}

The word "Academic" is defined as "to be judged by no other standard than the truth" (1) Academics disseminate their research findings through publications ${ }^{(2)}$; however, the gold standard for this dissemination is through publications in a prestigious peer-reviewed journal $^{(3)}$. The importance of research output is of triple benefits. It should create a positive impact on society according to the researcher's discipline ${ }^{(4)}$. Secondly, it influences ranking and reputation of the institution ${ }^{(5)}$. Thirdly, it gives a credit to the researcher in terms of promotion, getting fund grant, postgraduate certification and hiring (6). However, the outstanding purpose of the research is to serve the society. Unfortunately, a common trend for most of researchers is to adhere to the third benefit of research, seeking quantity rather than quality in their publication; hence, favoring merely personal credit. The advent of predatory journals and publishers that rapidly publish biased and/or poor study designs with no peer review imposed a big threat to the integrity of scientific research and became "the dark dangerous force" of publishing ${ }^{(7)}$.

Many thanks to the first attempt carried out by the American librarian Dr. Jeffrey Beall to preserve the academic research from this big deal of fake and predatory journals and publishers ${ }^{(8)}$. Fortunately, the invaluable effort of Jeffrey Beall was followed by many attempts to detect predatory journals and publishers like Dolos list by Professor Alexandre Georges ${ }^{(9)}$ and others.

The wide prevalence of predatory publication disease among academics is due to many causes: less publishing experiences among researchers, pressure to publish, lack of regulations governing academic integrity, promotion regulations that permit and give legitimacy to the publication in predatory journals ${ }^{(10)}$. Peer reviewing is the outmost evaluation tool of research quality. Lack of review processes in predatory journal publications led to low-quality research publications with no scientific value ${ }^{(11)}$.

Now the question how the higher education institutions immune their research output against the hazardous infection by predatory publication?

This may be accomplished by several preventive measures, some of them:

1- Establishment of scientific committees in each institution, comprised of experts in each discipline to be concerned with evaluation and setting scientific basis for research; e.g. ethical approval regulations, etc.

2- Planning firm regulations to govern academic integrity and honesty, with prohibition of any academic promotion based on publications in low-quality journals. 
3- Clear and firm governorate regulations against publishing in predatory journals.

4- Use clear parameters to assess the scientific quality and creditability of the journals.

5- Increase awareness of predatory journals among academic staff and most importantly postgraduate students through continuous and scheduled courses and workshops.

6- Create white and black journal lists and discourage researchers to publish in non-prestigious journals and abate them regularly.

\section{Summary}

In our modest point of view "research is not a paper published to increase the biography of an academic, nor a tool for getting fund, promotion and job. Research adds a great value to the society's life and can change the world; besides its reflection on a long-lasting impression of an academic, being his/her surviving wealth". To preserve science and society all over the world, we should ban fake research, fake journals and publishers. Finally, selecting prestigious journals for publishing scientific research is an issue of honesty.

\section{References}

1. "Academic" Research at University, by KarenKwokhttp://www.guide2research .com/wpcontent/uploads/2014/02/acad emic_research.

2. Neumann R. Research and scholarship: Perceptions of senior academic administrators, "Higher Education" 1993; 25 (2):97 -110.

3. Mayden KD. Peer Review: Publication's Gold Standard. J Adv Pract Oncol. 2012; 3(2):117-122.
4. Bornmann L. Measuring the societal impact of research: research is less and less assessed on scientific impact alonewe should aim to quantify the increasingly important contributions of science to society. EMBO Rep. 2012;13(8):673-676.

5. Beattie V, Goodacre A. Publication records of accounting and finance faculty promoted to professor: evidence from the UK, Accounting and Business Research, 2012; 42:2, 197-231.

6. Moher D, Naudet F, Cristea IA. et al. Assessing scientists for hiring, promotion, and tenure. PLoS Biol. 2018; 16(3): e2004089.

7. Brücher BLDM. Science belongs to no one-and to everyone. 4open, 2018; 1, E1

8. Jeffrey B. "Beall's List of Predatory Publishers 2014," Scholarly Open Access (blog).

http://scholarlyoa.com/2014/01/02/listof-predatorypublishers-2014

9. Georges A .Dolos list. List of predatory, parasitic, or pseudoscientific publishers and journals. Article published in September 2018.

10.Demir SB. Predatory journals: Who publishes in them and why? Journal of Informetrics. 2018; 12:1296-1311.

11.Kelly J, Sadeghieh T, Adeli K. Peer Review in Scientific Publications: Benefits, Critiques, \& A Survival Guide. EJIFCC. 2014; 25(3):227-43. 